\title{
On Tools Making Minds: an Archaeological Perspective on Human Cognitive Evolution
}

\author{
Karenleigh A. Overmann \\ University of Bergen, Norway \\ karenleigh.overmann@uib.no \\ Thomas Wynn \\ University of Colorado, Colorado Springs, USA \\ twynn@uccs.edu
}

\begin{abstract}
Using a model of cognition as extended and enactive, we examine the role of materiality in making minds as exemplified by lithics and writing, forms associated with conceptual thought and meta-awareness of conceptual domains. We address ways in which brain functions may change in response to interactions with material forms, the attributes of material forms that may cause such change, and the spans of time required for neurofunctional reorganization. We also offer three hypotheses for investigating co-influence and change in cognition and material culture.
\end{abstract}

\section{Keywords}

extended cognition - enactive cognition - literacy - lithics - cognitive evolution material engagement theory

Dolphins and bluefin tuna, as philosopher Andy Clark pointed out in 1997, have a greater-than-predicted swimming efficiency. They appear to realize this exceptional performance by exploiting the water's kinetic energy, something they either sense in the oceanic currents or create themselves motorically (Clark, 1997). Clark's fishy tale relates how an organism interacts with its environment: brain, body, and world are dynamically intertwined to a degree far beyond mere causal linkage. This may aptly describe the human adaptation

(C) KARENLEIGH A. OVERMANN AND THOMAS WYNN, 2019 | DOI:10.1163/15685373-12340047 This is an open access article distributed under the terms of the prevailing CC-BY license at the time of publication. 
as well, though our analog is material culture. That is, for both sea creature speeding through water and ourselves maneuvering and manipulating the physical world, cognition is extended (i.e., materiality is constitutive of cognition, not just casually linked to it) and enactive (cognition is the transformative interaction between brain, body, and world). Characterizing cognition as a dynamically interacting system lets us consider the material as both agentive influence upon and partner to our psychological and behavioral capabilities and capacities (Malafouris, 2008, 2013).

Over time, interaction with material forms can change psychological processing and behaviors. Here we examine two case studies in which this occurs: first, the emergence of literacy from the behavior of writing, which ultimately yielded meta-awareness of conceptual domains, and second, change in lithic technologies and associated behaviors that may index the emergence of conceptual thought. We focus on behavioral and psychological change resulting from interactions with material forms (while we acknowledge the genetic, environmental, and selective components of evolution, our inquiry is not how brains make tools but rather how tools make minds). We ground our analyses of the archaeological record in neuroscientific understandings of brain form and function. We suggest that (1) change in material forms imply change in particular brain functions, (2) material attributes and properties cause such changes, and (3) such changes are experientially imperceptible. We conclude with three hypotheses for investigating co-influence and change in cognition and material culture.

The parallels between tunas exploiting the ocean's kinetic energy and our own incorporation of material culture into our cognition may not be obvious. This is perhaps the result of the difference in dynamism, not in the organismenvironment interaction per se but in the environment itself, as water changes more immediately and perceptibly than do material objects under forces like invention, preference, wear, and age. Yet despite the seeming stasis of the material realm, our interaction with it is no less dynamic - no less fluid - than that between fish and water: we too connect, exploit, and disconnect with the material forms around us. Another reason the parallels are unobvious lies in the disparate temporalities of dynamic interactivity and accumulated change. The former is experienced in the moment; the latter takes years to millennia or longer to accumulate. The temporalities of change, which can span generations, tend to put it beyond our experience. Dynamic interactivity and accumulated change are not distinct, however, but connect and coalesce in the moment, where interactivity becomes collectivized and distributed within groups and societies. One of the mechanisms whereby this occurs is our use of materiality as a collaborative medium. 
As agent, partner, and collaborative medium, material artifacts interact with our psychological and physical abilities to pattern, habituate, and automate behaviors and skills, not only in individuals but in communities and societies as well. People who learn to drive or read and write become capable of manipulating particular material forms with specific bodily movements (e.g., arms and eyes) and psychological functions (e.g., attention). Tool use may affect both perception and body schema (Maravita, Husain, Clarke, \& Driver, 2001; Maravita, Spence, Kennett, \& Driver, 2002; Maravita \& Iriki, 2004), and engagement of a material form can become so automatic that the tool is transparent in its use, enabling attention to be refocused on other goals (Charlton \& Starkey, 2011; De Preester \& Tsakiris, 2009; Tucha, Tucha, \& Lange, 2008). Artifacts also help us decompose tasks and problems into smaller chunks (Hodder, 2012), which become easier to solve, especially collaboratively: not only are smaller problems generally easier to solve than larger ones, but decomposition facilitates the recruitment of potential problem solvers, and chunks can be distributed among individuals with different knowledge and skills (Hutchins, 1995). Artifacts also accumulate social and cultural knowledge in ways that mediate between what societies know and individuals learn (Haas, 1996) and which distribute cognitive effort over space and time, increasing the knowledge and decreasing the effort required by any particular individual or generation (Hutchins, 1995). Thus, we do not reinvent navigation or numbers, but rather learn, apply, and extend knowledge encoded in devices like the compass and abacus.

Interaction with material forms can also repurpose existing brain functions, as for example, training the fusiform gyrus to recognize written objects, cultural functionality that leverages an evolved role in recognizing physical objects (Dehaene et al., 2010; Dehaene \& Cohen, 2007; McCandliss, Cohen, \& Dehaene, 2003). What may be overlooked in neuronal recycling, however, is that learning to read and write means acquiring the ability to interact with a material form that is capable of eliciting particular behavioral and psychological responses, capability developed and refined through centuries of collaborative, distributed use (Overmann, 2016, 2017). The developmental process additionally ensures that as the material form is refined toward increasing effectiveness, it remains synchronized to average behavioral and psychological capabilities (Overmann, 2017). Certainly, writing underwent significant change in form: in Mesopotamia, initial signs with approximate semantic values and littleto-no phonetic specification became script capable of expressing the meanings and sounds of specific languages with fidelity (Hyman, 2006; Overmann, 2016; Sampson, 1999). While accumulating this change, writing nonetheless remained usable in common - requiring, in general, no unusual participant 
capacities in psychological functions like working memory or physiological/ behavioral capabilities like hand-eye coordination - through and because of the collaborative, distributed nature of its use and refinement. In turn, change in material form represents physiological/behavioral change in the participating members of the society, change they realized by interacting with the material form that in turn enabled them to change it further (Overmann, 2016). The iterative process of developing literacy and script from behaviors like handwriting and viewing conventionalized signs provides insight into ways that cognition and material culture can influence and change one another. It also raises intriguing possibilities for investigating co-influence and change in the more remote past.

Inferring Cognitive Change from the Material Record

Investigating the remote past is challenging, as neither cognition nor behavior can be directly observed or tested in extinct species. Skulls and endocranial casts provide insight into cerebral volume, gross morphology, and ontogenetic development (Bruner, 2004, 2010; Hublin, Neubauer, \& Gunz, 2015; Leigh, 2005) but do not reveal much about interior (soft-tissue) structure or psychological functioning. One can observe and measure the neurological function and structure of closely related non-humans (Nieder, 2013; Orban et al., 2006), which helps in identifying hominin-specific abilities but does not reveal when such differences appeared or their evolutionary context. Behaviors in extant species can be compared to those of extinct species, with similarities and differences assessed for cognitive implications (Wynn, Hernandez-Aguilar, Marchant, \& McGrew, 2011; Wynn \& McGrew, 1989). For extinct species, behaviors and cognition can be inferred from the archaeological and fossil records, and the archaeological record attests material change. Such analyses are complicated, however, by the vagaries governing archaeological/osteological preservation and discovery, the often-limited extent (how many related items) and duration (over what span of time) of samples, and various methodological and theoretical issues (Garofoli \& Haidle, 2014; Wynn, 2002).

One such theoretical issue is a lingering Cartesian division of brains from material forms (Malafouris, 2013). As a consequence, human cognitive evolution has been conceived as a story of brains becoming bigger and more capable over time (Bruner, Manzi, \& Arsuaga, 2003; Herculano-Houzel, 2009; Herculano-Houzel, Manger, \& Kaas, 2014; Kirk, 2006; Rightmire, 2004). As brains became bigger and more capable, behaviors and tools became more complex (Foley \& Lahr, 1997; Shea, 2017), circumstances plausibly related (Hecht et al., 2015; Johnson-Frey, 2004; Orban \& Caruana, 2014; Stout, Hecht, 


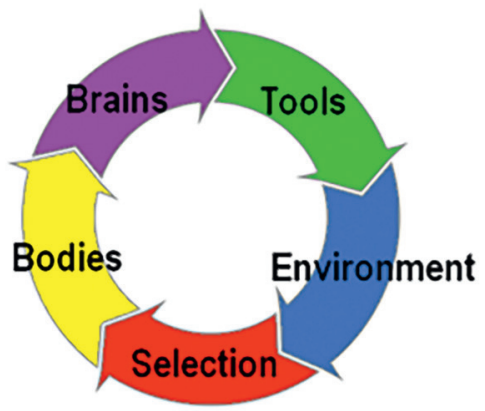

Brains make tools

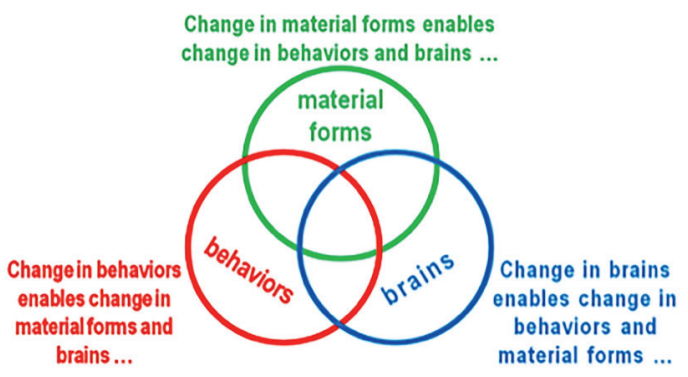

Tools make minds

FIGURE 1 In the "brains make tools" model (left), brains make tools that modify the environment, causing natural selection to act upon bodies, yielding the bigger, smarter brains that make better tools. In comparison, in the "tools make minds" model (right), behaviors with materiality change psychological processing in the brain, enabling new behaviors that yield changes in material forms.

Khreisheh, Bradley, \& Chaminade, 2015; Stout, Toth, Schick, \& Chaminade, 2008). Typically, increasing complexity in behaviors is explained as bigger brains enabling greater flexibility; for tools, as bigger, smarter brains creating better tools (Boyd, Richerson, \& Henrich, 2011; Coolidge \& Wynn, 2001; Donald, 1991; Heldstab et al., 2016; Mithen, 1996). Better tools certainly enabled ancestral species to access food resources more efficiently (Leonard, 2002), yielding the improved nutrition that was a factor in releasing selective pressure against larger brains (Isler \& Van Schaik, 2006).

If brains make tools, less well recognized is the potential for tools to influence behaviors and psychological processing (Malafouris, 2013; Fig. 1). This appears to have been the case with how literacy developed from handwriting, an interaction with a material form that yielded specific reorganizations and transformations to the human cognitive architecture (Overmann, 2016; Fig. 2). It could even be argued that behaviors with tools initialize processes of change, since they are demonstrated by species without language (Finn, Tregenza, \& Norman, 2009; Hall \& Schaller, 1964; Sanz, Call, \& Morgan, 2009) and with minimal levels of socially learned behaviors (Laland \& Janik, 2006), characteristics true of our own remoter ancestors. However, psychologicalbehavioral-material co-influence means that exact originating causes are often difficult to determine amidst multiple interacting variables, especially given the incompleteness and uncertainty of insight into events occurring in the remote past. Pinning down a prime mover is also perhaps unnecessary, since co-influence can be mutually reinforcing, and the resultant trajectories of change may have emergent effects that influence and intensify further change (Hodder, 2012; Overmann, 2015). One strategy, however, is starting from what 


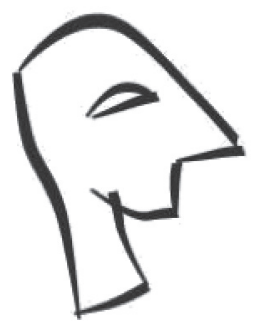

Pictograph meaning head, person, or capital, ca. 3200 B С

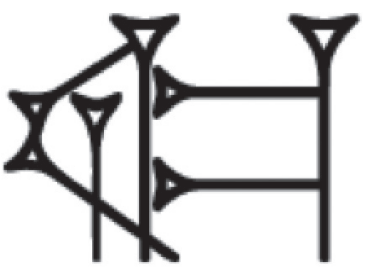

Character for the Sumerian word SAĞ, ca. 2500 BC

FIGURE 2 Two written characters from Mesopotamian writing separated by roughly 800 years. The later sign (right) is less depictive than the earlier one (left). The change in material form and concomitant behaviors like handwriting suggest the fusiform gyrus was becoming able to recognize characters by their features and topological relations, relaxing the need for depictiveness. A detailed analysis of change in Mesopotamian written forms and behaviors is presented in Overmann (2016), Fig. 9. Images adapted from the Cuneiform Digital Library (2015) and Pennsylvania Sumerian Dictionary (2015).

our ancestors shared with contemporary species - which is making, using, and discarding tools as an implicit part of behaviors associated with things like obtaining food - and then asking how and why interactions with tools might have changed behaviors and psychological processing over time, as inferred from change in material forms.

\section{2 \\ Stone Tools, Distinctive Behaviors, and Cognitive Implications}

The oldest artifacts able to inform scholarship about the evolution of hominin cognition are stones and bones: tools made of stone and the attendant debris of their manufacture and use, including bits of bones with marks on them from tools or teeth. Stone tools were not likely to have been the only forms of material culture used by early hominins (early Homo, and possibly the Australopithecus), nor butchery their only application, but stones and bones are what preserve over millions of years, along with teeth. Nonetheless, stone tools provide a surprising amount of insight into human cognitive evolution. The first, dating to between 2.6 and 3.3 million years ago (Ma), were sharp flakes produced by striking the edge of a stone "core" with a hammer stone (Harmand et al., 2015; Semaw, 2000). These tools appear to have been made, used, and discarded during processes of food extraction (e.g., butchering carcasses), behavior similar to that of modern non-human primates, who access sources of food with tools (e.g., rocks, twigs) created for the purpose and 
afterward discarded (Wynn et al., 2011; Wynn \& McGrew, 1989). Like modern non-human primates, these early hominins do not appear to have separated tools from their processes of use.

By about 1.7 Ma, hominins (at this point, Homo erectus) manufactured tools, but also carried them from place to place, keeping them for future use, a behavior not demonstrated by today's non-human primates. This curation suggests that tools had acquired status as permanent objects of daily life, perhaps with an attendant ontological concept distinguishing them from other kinds of objects (Wynn \& Gowlett, 2017). Hominins shaped some of their stone tools symmetrically, producing artifacts known as bifaces (Beyene et al., 2013; DiezMartín et al., 2015; Lepre et al., 2011; Wynn, 1989). Bifacial symmetry may have had its roots in the process of stone knapping (the conventional term for flaking stone) itself. When a stone knapper strikes a large number of flakes from a core, searching each time for an optimal place to strike, the core slowly takes on an oblong, vaguely lenticular shape (Moore \& Perston, 2016). Homo erectus began to accentuate certain ergonomic features of this oblong form in order to enhance its effectiveness as a large cutting tool: the tool's heft at the base ("glob butt"), forward and lateral extensions, working edge support, and thickness adjustment suggest their makers were attending to specific ergonomic features of the design (Gowlett, 2006; Fig. 3). In addition to ergonomic features, they also attended to visual features of the core itself, often accentuating the oblong form into a bilateral symmetry. In other words, hominins no longer made tools shaped just enough to get the job done (i.e., objects fitted to external purposes). Instead, they attended to design features and relationships within the form (objects whose internal features and relations were ends in themselves). Making these tools entailed sustained attention to their features (e.g., the glob butt and forward extension in relation to the whole artifact and to each other).

It was the engagement of earlier hominins with stone tools themselves that, arguably, acted as a scaffold for the development of a tool concept. Little of this interaction is visible in the archaeological record, but there are provocative hints. We know, for example, that even early on (i.e., before $3 \mathrm{Ma}$ ), hominins selected high quality raw material (Harmand et al., 2015). By 2.3 Ma, the evidence indicates that knappers examined cores closely for optimal places to strike off flakes (Delagnes \& Roche, 2005), and at about the same time, hominins carried cores, and occasionally finished flakes, long distances (up to 13 km) (Braun, Plummer, Ferraro, Ditchfield, \& Bishop, 2009). Close examination of cores implicates developments in attention, and carrying provided a temporal extension to tools and related activities to produce a curation in fact, if not yet in mind. 


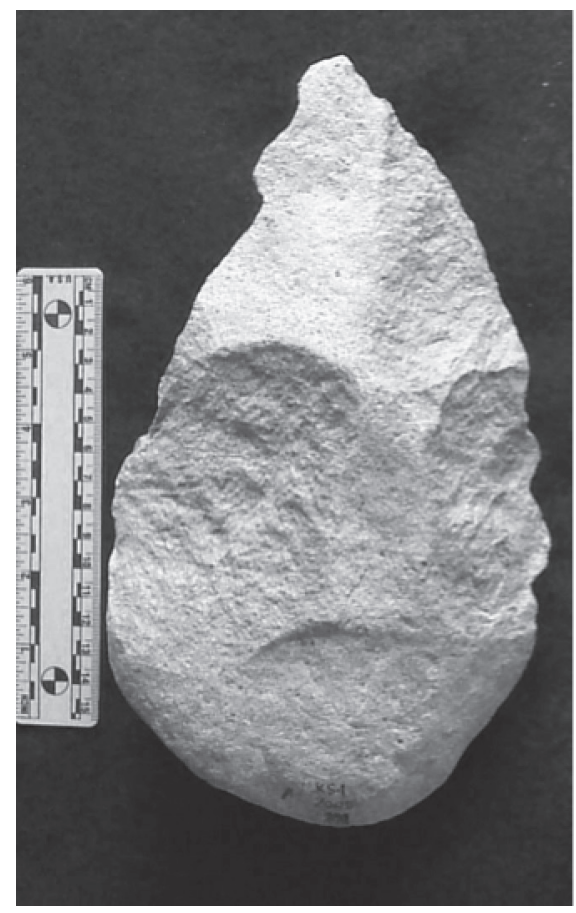

Handaxe from Kokiselei, Kenya, ca. 1.76 million years (Lepre et al., 2011)

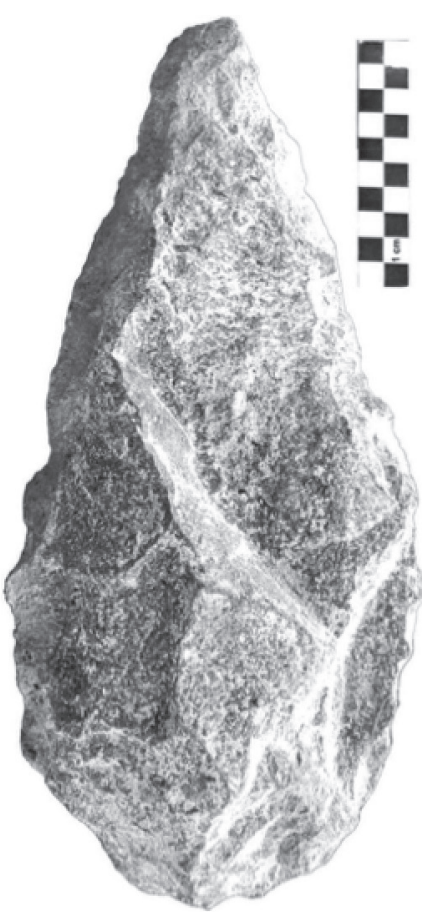

Handaxe from Olduvai Gorge, Tanzania, ca. 1.69 million years (Diez-Martín et al., 2015)

FIGURE 3 Two handaxes separated by about 70 thousand years. The more recent artifact (right) is more symmetrical than the older one (left). The difference in material form and attendant behavior show that its maker paid attention to and expended effort toward realizing symmetry, implying cognitive change. Previously published as Fig. 2 in Overmann and Wynn (2018).

Potential sequelae of these developments are with us still. Today we find the human intraparietal sulcus has non-homologous regions specialized for representing aspects of visual stimuli (Orban et al., 2006), the supramarginal gyrus is active when we use tools (Orban \& Caruana, 2014), and the angular gyrus is recruited for both finger movements and mathematical tasks (Andres, Seron, \& Olivier, 2007; Brooks, Barner, Frank, \& Goldin-Meadow, 2014; Frank \& Barner, 2012; Heimann, Umilta, \& Gallese, 2013; Penner-Wilger et al., 2007; Roux, Boetto, Sacko, Chollet, \& Trémoulet, 2003; Tschentscher, Hauk, Fischer, \& Pulvermüller, 2012). The importance of such parietal functions to both tools and concepts is significant, given that parietal enlargement is the single characteristic best differentiating the human brain from the brains of other primates, including ancestral species like $H$. erectus and closely related species 
like the Neandertals (Bruner, 2010; Bruner \& Manzi, 2008; Bruner et al., 2003). Evidence that motor movements and conceptual thought are related is also found in the cerebellum, another potential difference between the brains of H. sapiens and Neandertals (Pearce, Stringer, \& Dunbar, 2013; Weaver, 2005). Traditionally implicated in motor control and sequencing, the cerebellum appears to have a role in forming and manipulating abstract concepts as well (Balsters, Whelan, Robertson, \& Ramnani, 2013; Koziol, Budding, \& Chidekel, 2010; Vandervert, 2009; Vandervert, Schimpf, \& Liu, 2007), including those of numbers and mathematics (Vandervert, 2017).

The trajectory of change associated with stone tools suggests that the use of material objects as an implicit part of behaviors is not what differentiates humans, since this is shared with both ancestral and modern species. What may more truly distinguish us is us our ability to think about materiality - to form concepts of materiality in its absence, and to form concepts in seeming independence of any materiality - differences in behaviors and, plausibly, psychological processing associated with the curated tools of Homo erectus. Today our neurons form and manipulate concepts as if our bodies were behaviorally engaged with physically present materials. That is, the neural muscles that enable us to think about material forms emerged, at least in part, through several million years of patient stone knapping by ancestral species.

\section{3}

\section{Handwriting and Literacy}

If stone tools actualized the ability to form and manipulate concepts mentally, as if they were physical objects, writing might be said to have actualized the ability to form and manipulate concepts physically, as if they were mental objects. Reading is the interaction of psychological processes like objectrecognition and language (Adelman, Marquis, \& Sabatos-DeVito, 2010; Perfetti, 2003; Perfetti \& Tan, 2013), material forms like words on a page, and behaviors like handwriting that interface the two. The material form is writing, and change in its form over time represents change in behaviors and brains. In the late 4th millennium BC, writing in Mesopotamia began as pictures; over some 800 years, pictures turned into cuneiform (Krispijn, 2012; Nissen, Damerow, \& Englund, 1993; Veldhuis, 2014), a script that - unlike pictures - cannot be read without training. Interpreting this particular change in material form through the neuroscience of literacy suggests the following: handwriting taught brains to recognize characters by combinations of their local and global features and to associate them with the meanings and sounds of language. These training effects influenced change in the material form: for example, feature 
recognition relaxed the need for pictures to resemble the original objects, allowing them to become less depictive over time (Overmann, 2016). Change in form, thus, implies change in psychological processing. Change in form also necessitated increasingly formalized training, creating specialized practitioners like scribes, and this intensified behaviors and material-psychological change.

Across languages and scripts, core differences between literate and nonliterate brains include feature-recognition in the fusiform gyrus (i.e., Visual Word Form Area), its interaction with language functions, and activity in Exner's area (the frontal region adjacent to Broca's and the primary motor control area implicated in the movements specific to handwriting) (Klein et al., 2016; Pegado, Nakamura, \& Hannagan, 2014; Roux et al., 2009). As the interface between the psychological and material dimensions of writing, handwriting was critical to the development of literacy. Today it is known to improve things like fine motor skills, hand-eye coordination, recognition and recall functions, and tolerance for ambiguity in how characters are formed (James \& Engelhardt, 2012; Longcamp, Zerbato-Poudou, \& Velay, 2005; Mueller \& Oppenheimer, 2014; Sülzenbrück, Hegele, Rinkenauer, \& Heuer, 2011). In original contexts, handwriting would have provided a critical mechanism for adjusting and refining the material form of writing. Conditions in the late 4 th millennium $\mathrm{BC}$ were perfect for this continual tinkering: Mesopotamia was a state-level bureaucracy whose massive administrative requirements required generations to read and write the same signs with conventionalized meanings, hours per day and days over years. This interaction with the materiality of writing reorganized behaviors and brains, enabling further change to the material form. Within just a few centuries, the method of writing had become more efficient, as drawing curved lines was replaced by making wedge-shaped impressions (a matter influenced by the clay used for writing surfaces) (Cammarosano, 2014). A few centuries later, as signs were becoming less depictive, wedge-making order was becoming standardized, automaticity that would have enhanced lexical recall (Bramanti, 2015; Giovanni, 1994; Taylor, 2015) and freed cognitive capacity in psychological processes like attention for other purposes.

While Mesopotamian literacy may not represent a universal developmental process, it shares with other original contexts a repertoire of simple, conventionalized, non-numerical signs, written by hand for generations with the repetition frequency demanded by a state-level bureaucracy (Overmann, 2016). By 2000 BC, some 1500 years after writing began, literacy in Mesopotamia is signaled by several phenomena (Overmann, 2016): characters for words were no longer being split between lines of text (Cooper, 1996, 2004), an increased integrity of form that implies feature-recognition effects. Cursive, script with 
"abbreviated signs, crowded writing, and unclear sign boundaries" (Veldhuis, 2011, p. 72) had developed, suggesting tolerance for ambiguity. Writing was being applied to many new purposes (Veldhuis, 2011, 2012), suggesting it had achieved significant expressive power, and training had become highly formalized (Veldhuis, 2014), suggesting that script was opaque without it. The amount and rate of change also decreased around this time, though character form would continue to simplify, suggesting additional effects on attentional resources. That is, in modern scripts, a greater density of local features appears useful for novices but unnecessary and perhaps even detrimental for proficient readers (Bird, 1999; Ravid \& Haimowitz, 2006). Possibly the continued simplification of cuneiform characters after 2000 BC represents the discard of local features unneeded by proficient readers; this would likely have caused a concomitant increase in the effort required to acquire proficiency, at a time when, indeed, training was becoming more highly formalized.

\section{Investigating Co-Influence and Change in Cognition and Material Culture}

Lithics and writing raise three points for investigating co-influence and change in cognition and material culture. First, activity in Exner's area is important not only to producing writing but to comprehending it as well (Anderson, Damásio, \& Damásio, 1990), suggesting a neural muscle (Overmann \& Wynn, 2018). If indeed handwriting does become obsolete, as the encroachment of typing implies (Konnikova, 2014), Exner's area may continue to support comprehension, preserving neural activation once related to a specific productive behavior (handwriting) and perhaps tangentially involved in related behavior (typing). Understanding these antecedents, we might then deem this a neural fossil (Overmann \& Wynn, 2018). Activation continuity seems empirically verifiable and might, if supported, suggest that some of the activation associated with higher-level cognitive functions (e.g., in the parietal lobes or cerebellum) may be neural fossils related to productive behavior with material forms no longer in use (e.g., stone tools) that continue to respond to related material forms and behaviors. This in turn implies the development of a generalized neurological response to material culture (Overmann \& Wynn, 2018), a corollary to the way concepts can become distributed over multiple material forms to become effectively independent of any of them (Overmann, 2019).

Second, literacy involves, as lithic production once did, sustained attention on the features of material artifacts (e.g., design features in stone tools; the local and global features of written characters). Neither consisted of a passive 
visual inspection, but rather, motor movements that manipulate the material form concomitant with sustained attention to its features. Manipulation likely helped maintain interest, an element of sustaining attention, while habituation and then automation of the movements freed attentional capacity for purposes like attending to the content of writing and the patterns inherent in numerical sequences, rather than the mechanical production of characters and numbers. Sustained attention may be, therefore, an important mechanism for co-influence and change in cognition and material culture. This in turn suggests that research into the mechanisms whereby attention is focused, sustained, and balanced between competing stimuli (as it appears to be in diacritic markings, as mentioned previously) may be fruitful in providing insight into co-influential processes.

Third, concepts have been modeled as enactive blends of mental and material inputs, with the material component proposed to anchor and stabilize the resultant blends (Fauconnier \& Turner, 1998; Hutchins, 2005; Malafouris, 2013). If this is correct, then it suggests a possible mechanism for the development of greater complexity in psychological processes like categorization (Christie \& Gentner, 2007; Thompson \& Oden, 2000). That is, increased focus on design features of stone tools implies the ability to subdivide material forms, whose anchoring and stabilizing effects may be relatable to the complex hierarchical categorization ability in humans relative to other primate species. Writing certainly enabled materially represented ideas (e.g., all the professions performed by members of Sumerian society; all the stars known to the Babylonian astronomers) to be gathered, co-located (because they could be written together on the same clay tablet), manipulated (through the ability to reorganize them implied by rewriting and revising), and analyzed for their similarities and differences, implying, minimally, that the written medium enabled conceptual categories to be sharpened (Veldhuis, 2014; Watson \& Horowitz, 2011). Similarly, forming categories of relations (i.e., being able to ignore some features while attending to other, perhaps non-salient features) implies an ability to attend not just to wholes but also their parts, evoking ancestral concerns with the features of stone tools.

Granted, these hypotheses must be operationalized, highlighting the need for archaeology to engage the broad cognitive sciences. However, viewing cognition as extended and enactive admits new ways of thinking about the role of material forms within it: the story of human cognitive evolution may be one in which material interactions have changed behaviors and brains, enabling tool users to make subsequent, further changes to material forms. The iterative coinfluence we suggest for lithics and writing implies the idea that brains make tools must be at least supplemented by the idea that tools can also make minds. 


\section{References}

Adelman, J. S., Marquis, S. J., \& Sabatos-DeVito, M. G. (2010). Letters in words are read simultaneously, not in left-to-right sequence. Psychological Science, Vol. 21 (12), 1799-1801.

Anderson, S. W., Damásio, A. R., \& Damásio, H. (1990). Troubled letters but not numbers: Domain specific cognitive impairments following focal damage in frontal cortex. Brain, Vol. 113 (3), 749-766.

Andres, M., Seron, X., \& Olivier, E. (2007). Contribution of hand motor circuits to counting. Journal of Cognitive Neuroscience, Vol. 19 (4), 563-576.

Balsters, J. H., Whelan, C. D., Robertson, I. H., \& Ramnani, N. (2013). Cerebellum and cognition: Evidence for the encoding of higher order rules. Cerebral Cortex, Vol. 23 (6), 1433-1443.

Beyene, Y., Katoh, S., WoldeGabriel, G., Hart, W. K., Uto, K., Sudo, M., ... Asfaw, B. (2013). The characteristics and chronology of the earliest Acheulean at Konso, Ethiopia. Proceedings of the National Academy of Sciences of the United States of America, Vol. 110 (5), 1584-1591.

Bird, S. (1999). When marking tone reduces fluency: An orthography experiment in Cameroon. Language and Speech, Vol. 42 (1), 83-115.

Boyd, R., Richerson, P. J., \& Henrich, J. (2011). The cultural niche: Why social learning is essential for human adaptation. Proceedings of the National Academy of Sciences of the United States of America, Vol. 108 (Supplement 2), 10918-10925.

Bramanti, A. (2015). Rethinking the writing space: Anatomy of some early dynastic signs. In E. Devecchi, G. G. W. Müller, \& J. Mynářová (Eds.), Proceedings of the 6oe Rencontre Assyriologique Internationale, Warsaw 2014: Current research in cuneiform palaeography (pp. 31-47). Gladbeck, Germany: PeWe-Verlag.

Braun, D. R., Plummer, T. W., Ferraro, J. V., Ditchfield, P. W., \& Bishop, L. C. (2009). Raw material quality and Oldowan hominin toolstone preferences: Evidence from Kanjera South, Kenya. Journal of Archaeological Science, Vol. 36 (7), 1605-1614.

Brooks, N. B., Barner, D., Frank, M. C., \& Goldin-Meadow, S. (2014). Abacus: Gesture in the mind, not the hands. In P. Bello, M. Guarini, M. McShane, \& B. Scassellati (Eds.), Proceedings of the Cognitive Science Society (Vol. 36, pp. 72-73). Austin, TX: Cognitive Science Society.

Bruner, E. (2004). Geometric morphometrics and paleoneurology: Brain shape evolution in the genus Homo. Journal of Human Evolution, Vol. 47 (5), 279-303.

Bruner, E. (2010). Morphological differences in the parietal lobes with the human genus: A neurofunctional perspective. Current Anthropology, Vol. $5^{1}$ (1), S77-S88.

Bruner, E., \& Manzi, G. (2008). Paleoneurology of an "early" Neandertal: Endocranial size, shape, and features of Saccopastore 1. Journal of Human Evolution, Vol. 54 (6), 729-742. 
Bruner, E., Manzi, G., \& Arsuaga, J. L. (2003). Encephalization and allometric trajectories in the genus Homo: Evidence from the Neandertal and modern lineages. Proceedings of the National Academy of Sciences of the United States of America, Vol. 100 (26), 15335-15340.

Cammarosano, M. (2014). The cuneiform stylus. Mesopotamia, Vol. XLIX, 53-90.

Charlton, S. G., \& Starkey, N. J. (2011). Driving without awareness: The effects of practice and automaticity on attention and driving. Transportation Research Part F: Traffic Psychology and Behaviour, Vol. 14 (6), 456-471.

Christie, S., \& Gentner, D. (2007). Relational similarity in identity relation: The role of language. In S. Vosniadou, D. Kayser, \& A. Protopapas (Eds.), Proceedings of the 2nd European Cognitive Science conference (pp. 402-406). New York: Lawrence Erlbaum Associates.

Clark, A. (1997). Being there: Putting brain, body, and world together again. Cambridge, MA: Mit Press.

Coolidge, F. L., \& Wynn, T. (2001). Executive functions of the frontal lobes and the evolutionary ascendancy of Homo sapiens. Cambridge Archaeological Journal, Vol. 11 (3), 255-26o.

Cooper, J. S. (1996). Sumerian and Akkadian. In P. T. Daniels \& W. Bright (Eds.), The world's writing systems (pp. 37-57). New York: Oxford University Press.

Cooper, J. S. (2004). Babylonian beginnings: The origin of the cuneiform writing system in comparative perspective. In S. D. Houston (Ed.), The first writing: Script invention as history and process (pp. 71-99). Cambridge: Cambridge University Press.

Cuneiform Digital Library. (2015). Oxford: Oriental Institute, University of Oxford. Retrieved January 19, 2018 from: https://cdli.ucla.edu/.

De Preester, H., \& Tsakiris, M. (2009). Body-extension versus body-incorporation: Is there a need for a body-model? Phenomenology and the Cognitive Sciences, Vol. 8 (3), 307-319.

Dehaene, S., \& Cohen, L. (2007). Cultural recycling of cortical maps. Neuron, Vol. 56 (2), 384-398.

Dehaene, S., Pegado, F., Braga, L. W., Ventura, P., Filho, G. N., Jobert, A., ... Cohen, L. (2010). How learning to read changes the cortical networks for vision and language. Science, Vol. 330 (6009), 1359-1364.

Delagnes, A., \& Roche, H. (2005). Late Pliocene hominid knapping skills: The case of Lokalalei 2C, West Turkana, Kenya. Journal of Human Evolution, Vol. 48 (5), 435-472.

Diez-Martín, F., Yustos, P. S., Uribelarrea, D., Baquedano, E., Mark, D. F., Mabulla, A. Z. P., ... Domínguez-Rodrigo, M. (2015). The origin of the Acheulean: The 1.7 millionyear-old site of FLK West, Olduvai Gorge (Tanzania). Scientific Reports, Vol. 5 (17839), 1-9.

Donald, M. (1991). Origins of the modern mind: Three stages in the evolution of culture and cognition. Cambridge, MA: Harvard University Press. 
Fauconnier, G., \& Turner, M. (1998). Conceptual integration networks. Cognitive Science, Vol. 22 (2), 133-187.

Finn, J. K., Tregenza, T., \& Norman, M. D. (2009). Defensive tool use in a coconutcarrying octopus. Current Biology, Vol. 19 (23), R1069-R1070.

Foley, R. A., \& Lahr, M. M. (1997). Mode 3 technologies and the evolution of modern humans. Cambridge Archaeological Journal, Vol. 7 (1), 3-36.

Frank, M. C., \& Barner, D. (2012). Representing exact number visually using mental abacus. Journal of Experimental Psychology: General, Vol. 141 (1), 134-149.

Garofoli, D., \& Haidle, M. N. (2014). Epistemological problems in cognitive archaeology: An anti-relativistic proposal towards methodological uniformity. Journal of Anthropological Sciences, Vol. 92, 7-41.

Giovanni, F. B. d'Arcais. (1994). Order of strokes writing as a cue for retrieval in reading Chinese characters. European Journal of Cognitive Psychology, Vol. 6 (4), 337-355.

Gowlett, J. A. J. (2006). The elements of design form in Acheulian bifaces: Modes, modalities, rules and language. In N. Goren-Inbar \& G. Sharon (Eds.), Axe age: Acheulian tool-making from quarry to discard (pp. 203-222). London: Equinox.

Haas, C. (1996). Writing technology: Studies on the materiality of literacy. New York: Routledge.

Hall, K. R. L., \& Schaller, G. B. (1964). Tool-using behavior of the California sea otter. Journal of Mammalogy, Vol. 45 (2), 287-298.

Harmand, S., Lewis, J. E., Feibel, C. S., Lepre, C. J., Prat, S., Lenoble, A., ... Roche, H. (2015). 3.3-million-year-old stone tools from Lomekwi 3, West Turkana, Kenya. Nature, Vol. 521 (7552), 310-315.

Hecht, E. E., Gutman, D. A., Khreisheh, N., Taylor, S. V, Kilner, J., Faisal, A. A., ... Stout, D. (2015). Acquisition of Paleolithic toolmaking abilities involves structural remodeling to inferior frontoparietal regions. Brain Structure and Function, Vol. 220 (4), 2315-2331.

Heimann, K., Umilta, M. A., \& Gallese, V. (2013). How the motor-cortex distinguishes among letters, unknown symbols and scribbles: A high density EEG study. Neuropsychologia, Vol. 51, 2833-2840.

Heldstab, S. A., Kosonen, Z. K., Koski, S. E., Burkart, J. M., Van Schaik, C. P., \& Isler, K. (2016). Manipulation complexity in primates coevolved with brain size and terrestriality. Scientific Reports, Vol. 6 (24528), 1-9.

Herculano-Houzel, S. (2009). The human brain in numbers: A linearly scaled-up primate brain. Frontiers in Human Neuroscience, Vol. 3, 31.

Herculano-Houzel, S., Manger, P. R., \& Kaas, J. H. (2014). Brain scaling in mammalian evolution as a consequence of concerted and mosaic changes in numbers of neurons and average neuronal cell size. Frontiers in Neuroanatomy, Vol. 8 (77), 1-28.

Hodder, I. (2012). Entangled: An archaeology of the relationships between humans and things. Malden, MA: Wiley-Blackwell. 
Hublin, J.-J., Neubauer, S., \& Gunz, P. (2015). Brain ontogeny and life history in Pleistocene hominins. Philosophical Transactions of the Royal Society of London. Series B, Biological Sciences, Vol. 370 (1663), 1-11.

Hutchins, E. (1995). Cognition in the wild. Cambridge, MA: MIt Press.

Hutchins, E. (2005). Material anchors for conceptual blends. Journal of Pragmatics, Vol. 37 (10), 1555-1577.

Hyman, M. D. (2006). Of glyphs and glottography. Language \& Communication, Vol. 26, 231-249.

Isler, K., \& Van Schaik, C.P. (2006). Metabolic costs of brain size evolution. Biology Letters, Vol. 2 (4), 557-560.

James, K. H., \& Engelhardt, L. (2012). The effects of handwriting experience on functional brain development in pre-literate children. Trends in Neuroscience and Education, Vol. 1 (1), 32-42.

Johnson-Frey, S. H. (2004). The neural bases of complex tool use in humans. Trends in Cognitive Sciences, Vol. 8 (2), 71-78.

Kirk, E. C. (2006). Visual influences on primate encephalization. Journal of Human Evolution, Vol. 51 (1), 76-90.

Klein, E., Willmes, K., Jung, S., Huber, S., Braga, L. W., \& Moeller, K. (2016). Differing connectivity of Exner's area for numbers and letters. Frontiers in Human Neuroscience, Vol. 10, 1-9.

Konnikova, M. (2014, June 3). What's lost as handwriting fades. The New York Times, p. D1. Retrieved from https://www.nytimes.com/2014/06/03/science/whats-lost-as -handwriting-fades.html.

Koziol, L. F., Budding, D. E., \& Chidekel, D. (2010). Adaptation, expertise, and giftedness: Towards an understanding of cortical, subcortical, and cerebellar network contributions. Cerebellum, Vol. 9 (4), 499-529.

Krispijn, T. J. H. (2012). Writing Semitic with cuneiform script: The interaction of Sumerian and Akkadian orthography in the second half of the third millennium BC. In A. de Voogt \& J. F. Quack (Eds.), The idea of writing: Writing across borders (pp. 181-218). Leiden: Koninklijke Brill NV.

Laland, K. N., \& Janik, V. M. (2006). The animal cultures debate. Trends in Ecology and Evolution, Vol. 21 (10), 542-547.

Leigh, S. R. (2005). Brain ontogeny and life history in Homo erectus. Journal of Human Evolution, Vol. 50 (1), 104-108.

Leonard, W. R. (2002). Dietary change was a driving force in human evolution. Scientific American, Vol. 287 (6), 106-116.

Lepre, C. J., Roche, H., Kent, D. V, Harmand, S., Quinn, R. L., Brugal, J.-P., ... Feibel, C. S. (2011). An earlier origin for the Acheulian. Nature, Vol. 477 (7362), 82-85. 
Longcamp, M., Zerbato-Poudou, M.-T., \& Velay, J.-L. (2005). The influence of writing practice on letter recognition in preschool children: A comparison between handwriting and typing. Acta Psychologica, Vol. 119 (1), 67-79.

Malafouris, L. (2008). At the potter's wheel: An argument for material agency. In L. Malafouris \& C. Knappett (Eds.), Material agency: Towards a non-anthropocentric approach (pp. 19-36). New York: Springer Science + Business Media, LLC.

Malafouris, L. (2013). How things shape the mind: A theory of material engagement. Cambridge, MA: Mit Press.

Maravita, A., Husain, M., Clarke, K., \& Driver, J. (2001). Reaching with a tool extends visual-tactile interactions into far space: Evidence from cross-modal extinction. Neuropsychologia, Vol. 39 (6), 580-585.

Maravita, A., \& Iriki, A. (2004). Tools for the body (schema). Trends in Cognitive Sciences, Vol. 8 (2), 79-86.

Maravita, A., Spence, C., Kennett, S., \& Driver, J. (2002). Tool-use changes multimodal spatial interactions between vision and touch in normal humans. Cognition, Vol. 83 (2), B25-B34.

McCandliss, B. D., Cohen, L., \& Dehaene, S. (2003). The visual word form area: Expertise for reading in the fusiform gyrus. Trends in Cognitive Sciences, Vol. 7 (7), 293-299.

Mithen, S. J. (1996). The prehistory of mind: The cognitive origins of art, religion and science. London: Thames \& Hudson.

Moore, M. W., \& Perston, Y. (2016). Experimental insights into the cognitive significance of early stone tools. PLoS One, Vol. 11 (7), 1-37.

Mueller, P. A., \& Oppenheimer, D. M. (2014). The pen is mightier than the keyboard Advantages of longhand over laptop note taking. Psychological Science, Vol. 25 (6), 1159-1168.

Nieder, A. (2013). Coding of abstract quantity by "number neurons" of the primate brain. Journal of Comparative Physiology A: Neuroethology, Sensory, Neural, and Behavioral Physiology, Vol. 199 (1), 1-16.

Nissen, H. J., Damerow, P., \& Englund, R. K. (1993). Archaic bookkeeping: Early writing and techniques of economic administration in the ancient Near East. Translated by P. Larsen. Chicago: University of Chicago Press.

Orban, G. A., \& Caruana, F. (2014). The neural basis of human tool use. Frontiers in Psychology, Vol. 5, 1-12.

Orban, G. A., Claeys, K., Nelissen, K., Smans, R., Sunaert, S., Todd, J. T., ... Vanduffel, W. (2006). Mapping the parietal cortex of human and non-human primates. Neuropsychologia, Vol. 44 (13), 2647-2667.

Overmann, K. A. (2015). Teeth, tools and human becoming. Journal of Anthropological Sciences, Vol. 93, 163-167.

Overmann, K. A. (2016). Beyond writing: The development of literacy in the Ancient Near East. Cambridge Archaeological Journal, Vol. 26 (2), 285-303. 
Overmann, K. A. (2017). Thinking materially: Cognition as extended and enacted. Journal of Cognition and Culture, Vol. 17 (3-4), 381-400.

Overmann, K. A., \& Wynn, T. (2018). Materiality and human cognition. Journal of Archaeological Method and Theory, 1-22. https://doi.org/10.1007/s10816-018-9378-y.

Overmann, K. A. (2019). Concepts and how they get that way. Phenomenology and the Cognitive Sciences, Vol. 18 (1), 153-168.

Pearce, E., Stringer, C. B., \& Dunbar, R. I. M. (2013). New insights into differences in brain organization between Neanderthals and anatomically modern humans. Philosophical Transactions of the Royal Society of London. Series B, Biological Sciences, Vol. 280 (1758), 1-7.

Pegado, F., Nakamura, K., \& Hannagan, T. (2014). How does literacy break mirror invariance in the visual system? Frontiers in Psychology, Vol. 5, 1-5.

Penner-Wilger, M., Fast, L., LeFevre, J.-A., Smith-Chant, B. L., Skwarchuk, S.-L., Kamawar, D., \& Bisanz, J. (2007). The foundations of numeracy: Subitizing, finger gnosia, and fine motor ability. In D. S. McNamara \& J. G. Trafton (Eds.), Proceedings of the Cognitive Science Society (Vol. 29, pp. 1385-1390). Austin, TX: Cognitive Science Society.

Perfetti, C. A. (2003). The universal grammar of reading. Scientific Studies of Reading, Vol. 7 (1), 3-24.

Perfetti, C. A., \& Tan, L.-H. (2013). Write to read: The brain's universal reading and writing network. Trends in Cognitive Sciences, Vol. 17 (2), 56-57.

Ravid, D., \& Haimowitz, S. (2006). The vowel path: Learning about vowel representation in written Hebrew. Written Language and Literacy, Vol. 9 (1), 67-93.

Rightmire, G. P. (2004). Brain size and encephalization in Early to Mid-Pleistocene Homo. American Journal of Physical Anthropology, Vol. 124 (2), 109-123.

Roux, F., Boetto, S., Sacko, O., Chollet, F., \& Trémoulet, M. (2003). Writing, calculating, and finger recognition in the region of the angular gyrus: A cortical stimulation study of Gerstmann syndrome. Journal of Neurosurgery, Vol. 99 (4), 716-727.

Roux, F., Dufor, O., Giussani, C., Wamain, Y., Draper, L., Longcamp, M., \& Démonet, J. (2009). The graphemic/motor frontal area Exner's area revisited. Annals of Neurology, Vol. 66 (4), 537-545.

Sampson, G. (1999). Writing systems. In R. A. Wilson \& F. C. Keil (Eds.), The MIT encyclopedia of the cognitive sciences (pp. 894-896). Cambridge, MA: MIT Press.

Sanz, C. M., Call, J., \& Morgan, D. B. (2009). Design complexity in termite-fishing tools of chimpanzees (Pan troglodytes). Biology Letters: Animal Behaviour, Vol. 5, 293-296.

Semaw, S. (2000). The world's oldest stone artefacts from Gona, Ethiopia: Their implications for understanding stone technology and patterns of human evolution between 2.6-1.5 million years ago. Journal of Archaeological Science, Vol. 27 (12), 1197-1214. 
Shea, J. J. (2017). Stone tools in human evolution: Behavioral differences among technological primates. Cambridge: Cambridge University Press.

Stout, D., Hecht, E. E., Khreisheh, N., Bradley, B. A., \& Chaminade, T. (2015). Cognitive demands of Lower Paleolithic toolmaking. PLoS One, Vol. 10 (4), 1-18.

Stout, D., Toth, N. P., Schick, K. D., \& Chaminade, T. (2008). Neural correlates of Early Stone Age tool-making: Technology, language and cognition in human evolution. Philosophical Transactions of the Royal Society of London. Series B, Biological Sciences, Vol. 363 (1499), 1939-1949.

Sülzenbrück, S., Hegele, M., Rinkenauer, G., \& Heuer, H. (2011). The death of handwriting: Secondary effects of frequent computer use on basic motor skills. Journal of Motor Behavior, Vol. 43 (3), 247-251.

Taylor, J. (2015). Wedge order in cuneiform: A preliminary survey. In E. Devecchi, G. G. W. Müller, \& J. Mynářová (Eds.), Proceedings of the 6oe Rencontre Assyriologique Internationale, Warsaw 2014: Current research in cuneiform palaeography (pp. 1-30). Gladbeck, Germany: PeWe-Verlag.

Thompson, R. K., \& Oden, D. L. (2000). Categorical perception and conceptual judgments by nonhuman primates: The paleological monkey and the analogical ape. Cognitive Science, Vol. 24 (3), 363-396.

Tschentscher, N., Hauk, O., Fischer, M. H., \& Pulvermüller, F. (2012). You can count on the motor cortex: Finger counting habits modulate motor cortex activation evoked by numbers. NeuroImage, Vol. 59 (4), 3139-3148.

Tucha, O., Tucha, L., \& Lange, K. W. (2008). Graphonomics, automaticity and handwriting assessment. Literacy, Vol. 42 (3), 145-155.

University of Pennsylvania.(2015). The Pennsylvania Sumerian Dictionary. Philadelphia: Museum of Anthropology and Archaeology, University of Pennsylvania. Retrieved January 20, 2018 from: http://psd.museum.upenn.edu/epsdi/index.html.

Vandervert, L. R. (2009). The appearance of the child prodigy 10,000 years ago: An evolutionary and developmental explanation. Journal of Mind and Behavior, Vol. 30 (1), $15^{-}-32$.

Vandervert, L. R. (2017). The origin of mathematics and number sense in the cerebellum: With implications for finger counting and dyscalculia. Cerebellum \& Ataxias, Vol. 4 (12), 1-16.

Vandervert, L. R., Schimpf, P. H., \& Liu, H. (2007). How working memory and the cerebellum collaborate to produce creativity and innovation. Creativity Research Journal, Vol. 19 (1), 1-18.

Veldhuis, N. (2011). Levels of literacy. In K. Radner \& E. Robson (Eds.), The Oxford handbook of cuneiform culture (pp. 68-89). Oxford: Oxford University Press.

Veldhuis, N. (2012). Cuneiform: Changes and developments. In S. D. Houston (Ed.), The shape of script: How and why writing systems change (pp. 3-24). Santa Fe, NM: School for Advanced Research Press. 
Veldhuis, N. (2014). History of the cuneiform lexical tradition. Münster, Germany: Ugarit-Verlag.

Watson, R., \& Horowitz, W. (2011). Writing science before the Greeks: A naturalistic analysis of the Babylonian astronomical treatise MUL.APIN. Leiden: Brill.

Weaver, A. H. (2005). Reciprocal evolution of the cerebellum and neocortex in fossil humans. Proceedings of the National Academy of Sciences of the United States of America, Vol. 102 (10), 3576-3580.

Wynn, T. (1989). The evolution of spatial competence. Chicago: University of Illinois Press.

Wynn, T. (2002). Archaeology and cognitive evolution. Behavioral and Brain Sciences, Vol. 25 (3), 389-402.

Wynn, T., \& Gowlett, J. A. J. (2017). The handaxe reconsidered. Evolutionary Anthropology: Issues, News, and Reviews, Vol. 27 (1), 21-29.

Wynn, T., Hernandez-Aguilar, R. A., Marchant, L. F., \& McGrew, W. C. (2011). "An ape's view of the Oldowan" revisited. Evolutionary Anthropology: Issues, News, and Reviews, Vol. 20 (5), 181-197.

Wynn, T., \& McGrew, W. C. (1989). An ape's view of the Oldowan. Man, Vol. 24 (3), $383-398$. 